\title{
Bibliometric analysis of the journal Materiales de Construcción: 2013-2020
}

\author{
๑G. Mochón-Bezares ${ }^{\mathrm{a}}$, ®Á. Sorli-Rojob \\ a. University Carlos III, (Madrid, Spain) \\ b. Eduardo Torroja Institute for Construction Science (IETcc, CSIC), (Madrid, Spain) \\ : angela.sorli@ietcc.csic.es
}

Received 2 July 2021

Accepted 28 september 2021

Available on line 27 October 2021

\begin{abstract}
The objective of this study was to carry out an analysis of different bibliometric indicators of the journal Materiales de Construcción to verify the development of its scientific production between the years 2013 and 2020. The authors and their work institutions were analysed to check their productivity and degree of collaboration achieved, the levels of citation obtained in four impact indicators (Journal Impact Factor, 5-Year Impact Factor, Scimago Journal Rank and CiteScore) and the members of the editorial team of the journal to verify their permanence. The results show a high rate of collaboration between authors but somewhat scarce if considered by their work institutions, a significant increase in all the impact indicators consulted, and a reduction in the number of members of the editorial team. It is concluded that Materiales de Construcción journal has increased its internationality and considerably improved its impact between 2013 and 2020.
\end{abstract}

KEYWORDS: Construction; Scientific journals; Bibliometrics; Spain; Materiales de Construcción Journal.

Citation/Citar como: Mochón-Bezares, G.; Sorli, Á. (2021) Bibliometric analysis of the journal Materiales de Construcción: 20132020. Mater. Construcc. 71 [344], e268. https://doi.org/10.3989/mc.2021.10421.

RESUMEN: Análisis bibliométrico de la revista Materiales de Construcción: 2013-2020. El objetivo de este estudio fue realizar un análisis de distintos indicadores bibliométricos de la revista Materiales de Construcción para constatar el desarrollo de su producción científica entre los años 2013 y 2020. Se analizaron los autores y sus instituciones de trabajo para comprobar su productividad y el grado de colaboración alcanzado, los niveles de citación obtenidos en cuatro indicadores de impacto (Journal Impact Factor, 5-Year Impact Factor, Scimago Journal Rank y CiteScore) y los miembros del equipo editorial de la revista para comprobar su permanencia. Los resultados evidencian un alto índice de colaboración entre autores pero algo escaso si se considera por sus instituciones de trabajo, un importante incremento en todos los indicadores de impacto consultados, y una reducción del número de miembros del equipo editorial. Se concluye que la revista Materiales de Construcción ha incrementado su internacionalidad y mejorado considerablemente su impacto entre los años 2013 y 2020.

PALABRAS CLAVE: Construcción; Revistas científicas; Bibliometría; España; Revista Materiales de Construcción. 


\section{INTRODUCTION}

Of all the various ways scientists can report the results of their investigations, the most used way in the majority of sciences is the research journal. Researchers prefer scientific journals over other types of publication because their articles are evaluated by other specialists from the same subject area and because research journals follow the scientific method (1). In addition, the documents published in scientific journals adhere to certain patterns in terms of structure and presentation, and as a result different parameters of their contents can be subjected to metrics studies, yielding findings that the research community regards as reliable indicators of quality.

Research journal analyses usually sort publications into groups based on various kinds of criteria (e.g., geographic location, discipline, citations, time period) or their inclusion in certain databases or indices, for comparing publications' results to help define each journal's quality level. Metrics reviews focusing on a single journal are also performed, to assess the performance of a journal's various quantifiable elements in different time periods and to use the assessment results as a springboard for changes that could improve the journal's quality.

Many bibliometric analyses have focused on the group of scientific journals that share the building sciences as their core topic, especially papers on building information modelling (2-4). Few metrics analyses of Spanish construction journals have been published, however. Only one study dealing with Spanish journals as a group has been located in the Web of Science database's Construction \& Building Technology category, concerning the period from 1997 to 2008 (5). Two more articles about Spanish construction journals have been detected: one about the activity of Informes de la Construcción between 2007 and 2012 (6) and other one about Materiales de Construcción from 2003 to 2012 (7).

Materiales de Construcción is published by the Spanish National Research Council and edited by the Eduardo Torroja Institute for Construction Science. The journal prints studies concerning the properties, preservation, corrosion, deterioration and formation of construction materials, cement and concrete and studies of the effect construction materials, cement and concrete have on the environment, the use of waste, industrial by-products and other construction materials. It is listed in the most prestigious national and international databases, including not only those that provide citation indicators (JCR, Scimago Journal Rank), but also bibliographic databases (Scopus, WoS, SCI, Chemical Abstracts, Ceramic Abstracts, PASCAL, Metadex, Latindex). Its content has been available in free and open access since 1957 at the following link: http://materconstrucc.revistas.csic.es

Materiales de Construcción began its publishing career in early 1950 s under the title Últimos avances en materiales de construcción. It was then a sort of newsletter for the Technical Institute for Building and Cement, providing information about subjects in the institute's purview (8). In 1985 and later years, the journal's committee membership and its process for reviewing original articles were reworked, while greater efforts were aimed at improving the journal's visibility in international databases, especially Journal Citation Reports (JCR), which boosted the publication's prestige among authors (9). In 2013 the journal was subjected to a bibliometric analysis (7) that highlighted a significant proportion of Latin-American authors published, large number of non-Spaniards on the editorial team and a growth (with certain fluctuations) of its Impact Factor (IF). In more recent years the journal rolled out a number of changes; for example, it eliminated the technical notes section, it shifted to on-line publication only, and it now requires all articles to be written exclusively in English. All these alterations were designed to make the journal more international (10).

On the occasion of the seventieth anniversary of Materiales de Construcción, a new analysis has been carried out on different elements of the scientific production published in that journal and its editorial team over the last few years were subjected to analysis. The main objective of this paper is to evaluate the situation of Materiales de Construcción in late 2020, drawing comparisons between the data found in this analysis and the data obtained in a previous bibliometric analysis (7), with a view to tracing the development of various parameters over time, especially those referring to how international the journal is and how it ranks on lists of top-prestige journals.

\section{METHOD}

A descriptive retrospective bibliometric study of the scientific output published in Materiales de Construcción from 2013 to 2020 was conducted. The exploration of the journal looked only at the documents included in the "Research Articles" section, as these were the only articles in Materiales de Construcción that had undergone peer review.

The Web of Science (WoS) and Scopus databases were used to facilitate handling of the data on the documents at issue. These databases were consulted using the journal title ("Materiales de Construcción"), and the results were limited by document type (article) and the range of years targeted in the study (2013-2020). The results obtained in the consultation of these databases were merged in a single source in which the duplicates were eliminated. The information about members of the editorial team was obtained from the journal.

The bibliometric indicators stated below were examined. They are presented in groups according to data source: 
- Authorship. Authorship indicators measure the transient rate, which is the percentage of authors who contributed once in the entire period, and the co-authorship rate, which calculates the average number of authors per document. The most productive authors during the target period were also listed.

- Author institutions. Authors' affiliation, collected from the journal articles, were grouped by country and type, in order to find their geographical and type distribution.

- Impact factors. Development of annual figures and the rank of Materiales de Construcción in various impact indicators were traced. Two indices based on JCR were used: the Journal Impact Factor (JIF) and the 5-Year Impact Factor. These indices are found by dividing the number of citations that the documents published in a journal in the previous two (or five) years received in one year by the total number of documents that same journal published in the same two (or five) years $(10,11)$. Two Scopus-based indices were employed as well, the Scimago Journal Rank (SJR), which expresses the average number of weighted citations received in a year by the documents published in a journal during the previous three years (12), and CiteScore, which is based on the number of citations received by a journal's documents in the last four years divided by the number of documents published in those same four years (13).

- Members of the editorial team, which is made up of the editorial board and the advisory board. Information about these members was taken from the journal's website and from the printed editions available. The names, institutions and countries of the editorial team members throughout the period were gathered to determine member rotation, membership duration and board size.

The names of the authors and their work institutions were standardized to facilitate their man- agement. Data about authors and institutions were processed using social network analysis techniques, to discover what main actors were involved in the elements subjected to bibliometric analysis. Social networks were mapped using a free software tool, VOSviewer, version 1.6.16.

\section{RESULTS}

Between 2013 and 2020, Materiales de Construcción published a total of 271 research articles. The average number of papers per year was approximately 33.9. Temporal distribution of production was irregular, with a maximum of 39 articles in 2014 and a minimum of 30 in 2020.

\subsection{Authors}

There were 842 different authors between 2013 and 2020. Of these, 700 signed only one paper, which yields a transient rate of $83.4 \%$. The remaining 142 authors are distributed as follows: 97 $(11.52 \%)$ wrote two articles; 29 (3.44\%) wrote three articles; eight $(0.95 \%)$ wrote four articles; and eight $(0.95 \%)$ wrote five or more articles. Table 1 gives the names of the most prolific authors (most of them Spanish researchers) and their affiliation.

The co-authorship rate for the entire period was 3.97 authors per article. The lowest rate appeared in 2013 and 2017, with 3.7 authors per article, and the highest, in 2020, with an average of 4.51 authors. Only eight single-author articles were recorded, which means that $97.05 \%$ of the entire set was made in collaboration among multiple authors.

According to their degree of collaboration, the leading pairs of authors are the following, listed according to their productivity: with five articles, F. Moreno-Navarro and M.C. Rubio-Gámez, from the University of Granada; with four articles, C. Argiz and M.A. Sanjuán, from the Polytechnic University of Madrid, S. Cavalaro and A. Aguado from the

TABLE 1. Most prolific authors from 2013 to 2020.

\begin{tabular}{|c|c|c|c|}
\hline Author & Affiliation & Country & Num. papers \\
\hline Mejia de Gutierrez, R. & Univ. Valle (Cali) & Colombia & 9 \\
\hline Aguado, A. & Univ. Politecn. Cataluña (Barcelona) & Spain & 8 \\
\hline Galvez, J. C. & Univ. Politecn. Madrid & Spain & 7 \\
\hline Moreno-Navarro, F. & Univ. Granada & Spain & 6 \\
\hline Puertas, F. & Eduardo Torroja Inst. Construct. Sci. (Madrid) & Spain & 5 \\
\hline Rubio-Gamez, M. C. & Univ. Granada & Spain & 5 \\
\hline Tobon, J. I. & Univ. Nacl. Colombia (Bogota) & Colombia & 5 \\
\hline Paya, J. & Univ. Politecn. Valencia & Spain & 5 \\
\hline
\end{tabular}


Polytechnic University of Catalonia, and M.V. Borrachero and J. Paya, from the Polytechnic University of Valencia. Four articles were also published by the group formed by J.M. Almanza, D.A. Cortés, J.C. Escobedo and J.I. Escalante-García, all of whom belong to the Centre for Research and Advanced Studies (CINVESTAV) of Mexico.

\subsection{Institutions}

In the information of the 842 authors identified, 234 different work institutions were collected. They were grouped by type as follows: 176 universities and institutions of higher education, 34 research institutes and centres, 17 private companies (almost all in the chemical or building industry) and seven government agencies. The universities and institutes of higher education had the highest number of authors $(697,82.48 \%$ of the total), especially Spanish universities, which accounted for 281 authors. These were followed by research institutes, with 115 authors $(13.61 \%), 37$ of them was connected with the Eduardo Torroja Institute for Construction Science. After these came private companies, with 26 authors $(3.08 \%)$, and government agencies, with seven authors $(0.83 \%)$.

The 234 institutions identified were distributed in 51 countries. Spain had the highest percentage of authors. At the top of the list of the remaining countries were three geographical areas: Europe (not including Spain), Asia and Latin America. The European group was made up of 21 countries, with Portugal in the lead, and it accounted for $20.66 \%$ of the total. The Asian set contained fifteen countries, with the People's Republic of China in first place, and alto- gether had $17.1 \%$ of all authors. Latin America was represented by just six countries, although most of them had a large number of authors, as can be seen in Table 2. The lowest percentages belonged to four African countries: Egypt (1.43\%), Algeria (0.71\%), Nigeria $(0.59 \%)$ and Morocco $(0.48 \%)$, and a number of English-speaking countries: the United States $(0.7 \%)$, Australia $(0.36 \%)$ and Canada $(0.12 \%)$.

Co-authorship was scarce according to authors' affiliation. Only staff from 88 of the 234 institutions $(37.06 \%)$ published in partnership with researchers from other organizations. Figure 1 contains an inter-institution co-authorship network showing which nodes had the highest number of relationships with other nodes. The biggest nodes on co-authorship by

TABLE 2. Countries with high number of authors

\begin{tabular}{lcc}
\hline \multicolumn{1}{c}{ Country } & Num. authors & Perc. \\
\hline Spain & 369 & $43.82 \%$ \\
\hline Portugal & 49 & $5.82 \%$ \\
\hline People Repub. China & 49 & $5.82 \%$ \\
\hline Brazil & 35 & $4.16 \%$ \\
\hline Colombia & 30 & $3.56 \%$ \\
\hline Turkey & 25 & $2.97 \%$ \\
\hline Mexico & 24 & $2.85 \%$ \\
\hline Malaysia & 24 & $2.85 \%$ \\
\hline Argentina & 16 & $1.90 \%$ \\
\hline United Kingdom & 15 & $1.78 \%$ \\
\hline Italy & 15 & $1.78 \%$ \\
\hline Serbia & 15 & $1.78 \%$ \\
\hline
\end{tabular}

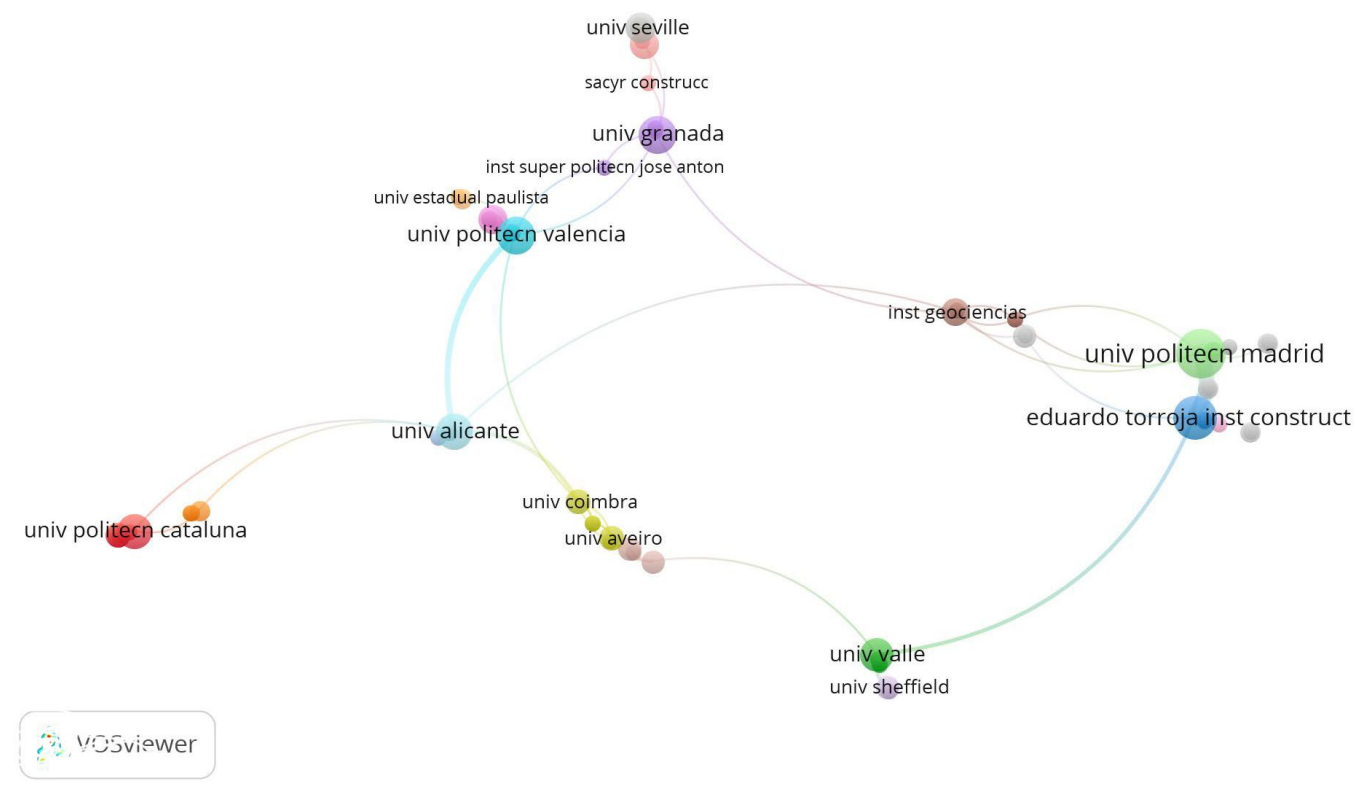

FIGURE 1. Network of co-authorship by institution. 
institution correspond to Madrid Polytechnic University, the Eduardo Torroja Institute for Construction Science, Valencia Polytechnic University and the University of Alicante, with 15, 14, 11 and 10 links, respectively, which represent the number of articles that their authors have co-signed with authors from other institutions. The University of Alicante node attains a higher degree of intermediation than the others, as it connects several clusters in the network.

\subsection{Editorial team}

From 2013 to 2020, a total of 48 people made up the editorial team, 19 on the editorial board and 29 on the advisory board. They came from 31 institutions. Throughout the entire eight-year period the editorial board had a steady 13 members, six of whom were replaced in 2019, while the advisory board ranged in size from 21 members in 2013, rising to 25 in 2015 and later shrinking to 15 members in 2020, at the end of the period.

The members of the editorial team were from many nations. Spain had the highest percentage of institutions represented on the editorial team (45.16\%), Italy and the United Kingdom had two institutions each $(6.45 \%)$, and a group of thirteen countries had only one institution each (Argentina, Belgium, Brazil, China, Colombia, Egypt, Hungary, India, Mexico, Portugal, Sweden, Switzerland and the USA). Broken down by type, the institutions on the editorial team were mainly universities $(61.3 \%)$ followed by research institutions and laboratories $(38.7 \%)$.

On the editorial board only one of 19 people declared an association with a foreign entity, and for only a brief time (S.H. Pialarissi in 2020). The other board members belonged to Spanish institutions. From 2013 to 2019 the editorial board showed a certain concentration of staff from the Eduardo Torroja
Institute for Construction Science (four members) and Madrid Polytechnic University (three members). In 2020 some members were replaced, after which the two institutions had the same number of representatives on the editorial board.

On the advisory board there were 24 institutions from 16 countries that had representatives at some time. Spanish organizations were the most prominent. The Eduardo Torroja Institute for Construction Science accounted for an important portion of the advisory board too, with five members during the eight-year period analysed, as did Madrid Polytechnic University, with three members.

\subsection{Impact factors}

Journal impact rates were measured by taking the annual JIF, 5-Year Impact Factor, CiteScore and SJR figures. These data are given together in Figure 2 to show the development of each index during the period at issue.

Beginning with the JCR-based impact indicators, the JIF trended upward, with hefty increases in 2016 and 2017, then in 2019 it slumped, losing much of the accumulated increase of the previous three years, although in 2020 there was another important rise. Increases and decreases appeared in the 5-Year Impact Factor in the same yearly periods as in the JIF, although they were not as sharp as in the two-year index and with a very important rise in the last year of the period studied as can be seen in Figure 2.

Moving on to the impact indicators based on Scopus citations, CiteScore showed a development similar to the JIF's, with major yearly increases starting in 2016, although in this case the index's decline began in 2019 and was not as steep. The SJR displayed a different course of development, moving slightly upward in 2014 and rising suddenly in 2017, followed by a gentle decline until 2020 .

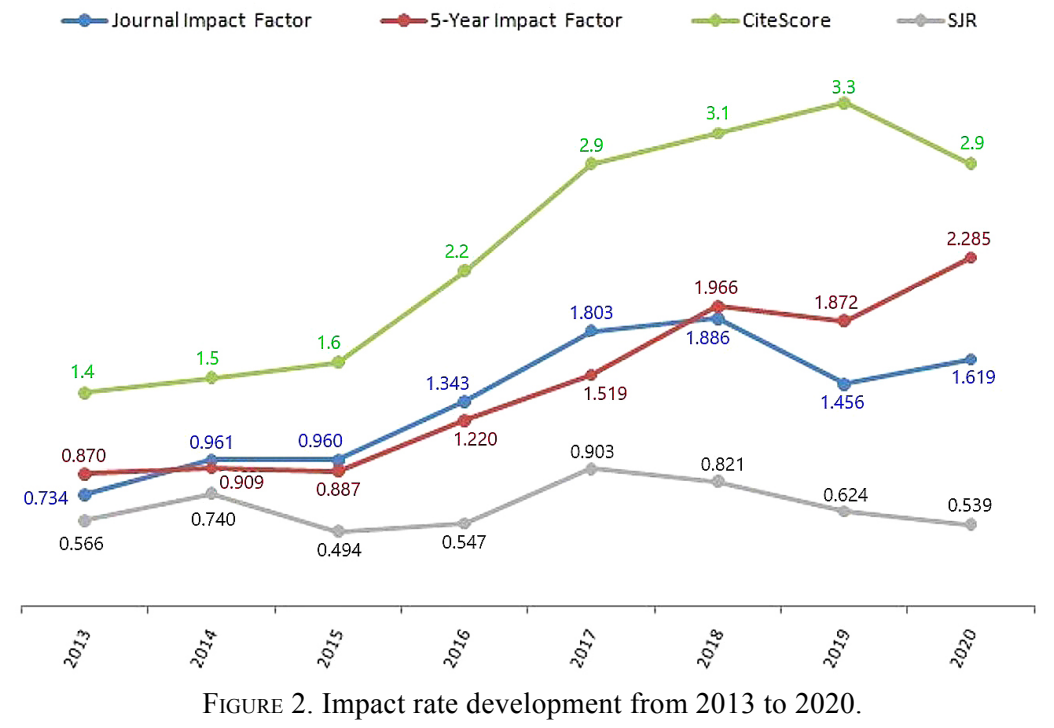




\section{DISCUSSION AND CONCLUSIONS}

Both the generic and the specific indicators discussed in this paper suggest that Materiales de Construcción made favourable progress between 2013 and 2020, increasing its international distribution and improving its position among high-prestige journals in the areas of materials and building sciences and building technology in the leading international databases. To record the journal's development, this study's main findings were compared with the findings reported in an earlier paper evaluating the journal's indicators from 2003 to 2012 (7).

Author productivity was one point considered. Between 2003 and 2012 the average number of authors per paper was 2.6 in technical notes and 3.56 in research articles, while from 2013 to 2020 up to 3.97 authors per article were registered. In addition, the number of single-author papers declined considerably; the figure fell from $5.88 \%$ in the first period to $2.95 \%$ in the more recent stage. The decline in single-author papers and the rise in the average number of authors per article indicate an increase in collaboration among the researchers who publish in Materiales de Construcción.

The number of authors who contributed to the journal once during the entire cycle (transient rate) rose from $78.53 \%$ in the decade between 2003 and 2012 to $83.4 \%$ in the more recent period (20132020), and the percentages corresponding to groups of two, three, four and five or more authors fell slightly.

Comparison of the author institution figures for the two periods reveals an important difference between the data sets. From 2003 to 2012, authorship was highly concentrated in the Spanish-speaking countries (over $83 \%$ of authors), while in the period from 2013 to 2020 the number of authors from Spanish-speaking countries shrank significantly, to $53 \%$ of the total. Meanwhile, authors from other geographical areas increased their presence considerably in the second period. Such is the case of European authors, who rose from $9.47 \%$ to $20.6 \%$, and Asian authors, who accounted for over $17 \%$.

Consideration of authors' home institutions by type shows a tendency to concentration in universities and institutions of higher education, which rose from $58.3 \%$ in $2003-2012$ to $75.2 \%$ in the more recent period, and a major decline in research institutes, from $22.2 \%$ to $14.5 \%$.

The editorial team had some slight changes between what was observed in the analysis carried out in 2013 (7) and the present study. There was a decline in the total number of members (from 54 to 48) and institutions (from 33 to 31). Membership percentages remained steady for the institutions with the greatest presence on the editorial team: Eduardo Torroja Institute for Construction Science $(18.5 \%$ in 2003-2012 and 18.75\% in 2013-2020) and Madrid
Polytechnic University (12.96\% in 2003-2012 and $12.5 \%$ in $2013-2020$ ). The country distribution of the institutions has also varied only slightly, increasing from 15 to 16 countries.

The rise in impact factors of the journal from the figures found in the study published in 2013 (7) was considerable. In the case of the JIF, the figures have doubled during the period studied (from 0.734 in 2013 to 1.619 in 2020), while those related to 5-Year Impact Factor have increased by more than $250 \%$ (from 0.870 in 2013 to 2.285 in 2020). Although the figures of the impact indicators of this journal have decreased slightly in some years, it can be considered that the increase in the number of citations received during the entire period studied implies a better acceptance of the content published in Materiales de Construcción by researchers.

\section{AUTHOR CONTRIBUTIONS:}

Investigation: G. Mochón-Bezares, Á. Sorli-Rojo. Methodology: G. Mochón-Bezares, Á. Sorli-Rojo. Roles/Writing, original draft: G. Mochón-Bezares, Á. Sorli-Rojo. Writing - review \& editing: G. Mochón-Bezares, Á. Sorli-Rojo.

\section{REFERENCES}

1. Delgado López-Cozar, E.; Ruiz-Pérez, R; JiménezContreras, E. (2007). La edición de revistas científicas: Directrices, criterios y modelos de evaluación. Granada: Fundación Española para la Ciencia y la Tecnología. Disponible en: https://www.fecyt.es/es/publicacion/laedicion-de-revistas-cientificas-directrices-criterios-ymodelos-de-evaluacion.

2. Santos, R.; Costa, A.A.; Grilo, A. (2017). Bibliometric analysis and review of Building Information Modelling literature published between 2005 and 2015. Automation in construction. Autom. Constr. 80, 118-136. https://doi. org/10.1016/j.autcon.2017.03.005.

3. Wu, Z.; Chen, C.; Cai, Y.; Lu, C.; Wang, H.; Yu, T. (2019) BIM-based visualization research in the construction industry: A network analysis. Int. J. Environ. Res. Public Health. 16 [18], 3473. https://doi.org/10.3390/ijerph16183473.

4. Rojas-Sola, I.; Aguilera-García, A.I. (2020). Global bibliometric analysis of building information modelling through the Web of Science core collection (2003-2017). Inf. Constr. 72 [557], e323. https://doi.org/10.3989/ic.66768.

5. Rojas-Sola, J.I.; de San-Antonio-Gómez, C. (2010) Análisis bibliométrico de las publicaciones científicas españolas en la categoría Construction \& Building Technology de la base de datos Web of Science (1997-2008). Mater. Construcc. 60 [300], 143-149. https://doi.org/10.3989/mc.2010.59810.

6. Sorli-Rojo, Á.; Mochón-Bezares, G. (2014). Informes de la Construcción: un análisis bibliométrico (2007-2013). Inf. Construc. 66 [536], e041. https://doi.org/10.3989/ic.14.108.

7. Sorli-Rojo, Á.; Mochón-Bezares, G. (2013). "Materiales de Construcción" Journal, 2003-2012: a bibliometric analysis. Mater. Construcc. 63 [312], 613-621. https://doi.org/10.3989/ mc.2013.07513.

8. Calleja, J. (2001). Fiftieth anniversary of the journal «Últimos Avances en Materiales de Construcción». Mater. Construcc. 51 [263-264], 7-27. https://doi.org/10.3989/mc.2001.v51. i263-264.349.

9. Puertas, F.; Alonso, M.M.; Vázquez, T. (2008). La Revista "Materiales de Construcción". Historia, situación actual y perspectivas. Inf. Constr. 60 [510], 81-86. https://doi. org/10.3989/ic.2008.v60.i510.732. 
10. Clarivate (2018). Journal Citation Reports: Document types included in the impact factor calculation. https://support. clarivate.com/ScientificandAcademicResearch/s/article/ Journal-Citation-Reports-Document-Types-Included-in-theImpact-Factor-Calculation?language $=$ en_US.

11. Clarivate (2018). Journal Citation Reports: 5-Year impact factors. https://support.clarivate.com/ ScientificandAcademicResearch/s/article/Journal-Citation-
Reports-5-Year-Impact-Factors?language=en US.

12. SCImago Journal \& Country Rank (2007). Description of Scimago Journal rank indicator. https://www.scimagojr.com/ SCImagoJournalRank.pdf.

13. Scopus (2020). CiteScore Journal Metric - FAQs - Scopus: Access and use Support Center. https://service.elsevier.com/ app/answers/detail/a_id/30562/supporthub/scopus/. 